\section{STUDI EVALUASI PENEMPATAN RAMBU DAN MARKA TERHADAP GEOMETRIK JALAN DI KECAMATAN TERNATE BARAT}

Chairul Anwara, Muhammad Taufiq Yuda Saputra ${ }^{\text {* }}$,

Article history

Received

Received in revised form

Accepted

aUniversitas Khairun, Ternate, Indonesia
* Corresponding author taufiqyudasaputra@gmail.com

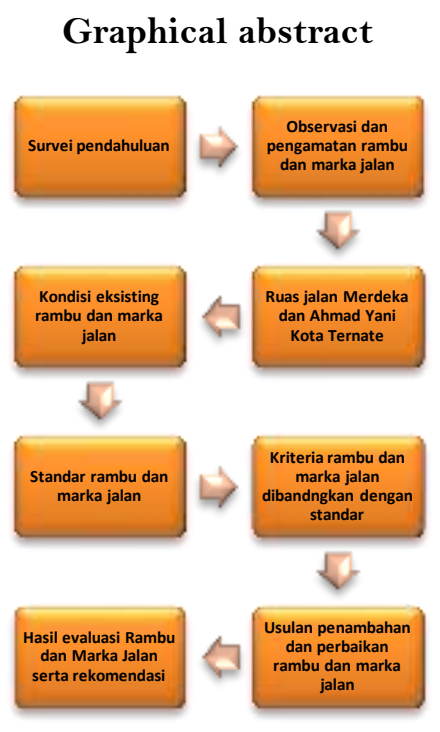

\begin{abstract}
About $90 \%$ of the information needed to drive is received by the driver visually through the eye. Little information is received by hearing (horns, shock markers) and sense of taste (rough profile/walking markers). The research objective was to evaluate the performance of traffic signs and road markings on several roads in Ternate City.

This type of research is a combination of direct field surveys and observations as well as literature (literature) related to the placement of signs and markers in accordance with urban road traffic standards. This research was conducted on Jalan Merdeka and Jalan Ahmad Yani, Ternate City with the consideration that these roads have a fairly high traffic density.

The results of the survey and observation of the condition of signs and road markings for Jalan Merdeka and Jalan Ahmad Yani in Ternate City, namely: there are still traffic signs that are not maintained and the condition of the signs is damaged. It is necessary to repair the leaf signs and repainting it. In some direction signs, the shape and size of the writing do not meet the standards of the Minister of the Republic of Indonesia No. 61 of 1993. Recommendations for placing signs and markings on roads with incomplete road equipment are as follows: warning signs for intersections, warning signs for $\mathrm{T}$-junction, crossing signs and placing signs for public facilities.
\end{abstract}

Keywords: Signs, Road Markings, Standards

\begin{abstract}
Abstrak
Sekitar 90\% informasi yang diperlukan untuk mengemudi, diterima oleh pengemudi secara visual melalui mata. Hanya sedikit informasi yang diterima dengan pendengaran (klakson, marka kejut) dan indera perasa (marka berprofil/jalan kasar). Tujuan penelitian untuk mengevaluasi kinerja rambu lalu lintas dan marka jalan yang ada pada beberapa ruas jalan di Kota Ternate.

Jenis penelitian yang dilakukan merupakan gabungan dari survei dan observasi lapangan secara langsung serta literatur (kepustakaan) yang berhubungan/berkaitan dengan penempatan rambu dan marka yang sesuai dengan standar lalu lintas jalan perkotaan. Penelitian ini dilakukan di ruas jalan Merdeka dan Jalan Ahmad Yani Kota Ternate dengan pertimbangan bahwa ruas jalan tersebut memiliki kepadatan arus lalu lintas yang cukup tinggi

Hasil survey dan observasi kondisi rambu dan marka jalan ruas jalan Merdeka dan Jalan Ahmad Yani di Kota Ternate yaitu : masih terdapat rambu lalu lintas yang tidak terawat dan kondisi rambu yang rusak. Di perlukan perbaikan pada daun rambu dan pengecatan kembali.Pada beberapa rambu penunjuk jurusan, bentuk dan ukuran tulisan tidak memenuhi standar Kepmen RI No. 61 Tahun 1993. Rekomendasi penempatan rambu dan marka pada ruas jalan yang belum lengkap fasilitas perlengkapan jalan yaitu sebagai berikut: rambu peringatan perempatan, rambu peringatan pertigaan, rambu penyebrangan serta penempatan rambu petunjuk fasilitas umum.
\end{abstract}

Kata kunci : Rambu, Marka Jalan, Standar.

(C) 2021 Penerbit Fakultas Teknik Unkhair. All rights reserved 


\subsection{INTRODUCTION}

Kecamatan Ternate Barat yang merupakan pemekaran dari Kecamatan Pulau Ternate membawahi 7 kelurahan, yaitu Togafo, Loto, Takome, Sulamadaha, Tobololo, Bula dan Kulaba.

Dalam undang-undang No. 14 Tahun 1992, tentang lalu lintas dan angkutan jalan. Dijelaskan bahwa untuk keselamatan, keamanan, ketertiban, dan kelancaran lalu lintas serta memudahkan bagi pemakai jalan, maka jalan wajib dilengkapi dengan rambu-rambu lalu lintas. Disamping itu dalam tata laksana lalu lintas upaya-upaya dalam menuntun, mengarahkan, memperingatkan, melarang dan sebagainya atau lalu lintas yang ada dengan sedemikian rupa agar lalu lintas dapat bergerak dengan aman, lancar dan nyaman di sepanjang jalur lalu lintas maka dibutuhkan penggunaan rambu-rambu lalu lintas.

Rambu lalu-lintas di jalan yang selanjutnya disebut rambu adalah salah satu dari perlengkapan jalan, berupa lambang, peringatan, larangan, perintah atau petunjuk bagi pemakai jalan. Ada 3 jenis informasi yang digunakan yaitu, 1) Yang bersifat perintah dan larangan yang harus di patuhi. 2) Peringatan terhadap suatu bahaya. 3) Petunjuk, berupa arah, identifikasi tempat, fasilitas-fasilitas. Dalam keberadaan rambu dilapangan ada beberapa syarat agar rambu dapat berfungsi dengan baik. Beberapa syarat tersebut antara lain adalah sebagai berikut: a) Dapat terlihat dengan jelas. b) Memaksakan perhatian. c) Menyampaikan maksud yang jelas dan sederhana. d) Memberikan waktu yang cukup untuk menanggapinya/bereaksi. e) Mudah di pahami 2.1. Rambu lalu lintas Menurut Undang-Undang No. 22 tahun 2009 tentang lalu lintas dan angkutan jalan rambu lalu lintas adalah bagian dari perlengkapan jalan yang berupa lambang, huruf, angka, kalimat, yang berfungsi sebagai peringatan, larangan, perintah, atau petunjuk bagi pengguna jalan. 2.2. Marka jalan Menurut Undang-Undang No. 22 tahun 2009 tentang lalu lintas dan angkutan jalan marka jalan adalah tanda berupa garis, gambar, anak panah, dan lambang pada permukaan jalan yang berfungsi mengarahkan arus lalu lintas dan membatasi kepentingan lalu lintas. Posisi marka jalan adalah membujur, melintang, dan serong. Tentang marka jalan diatur dalam PP No. 43 Tahun 1993 tentang Prasarana dan lalu lintas jalan dan PP No.13 Tahun 2014 tentang Rambu lalu lintas.

Pentingnya penggunaan rambu lalu lintas dan marka jalan sebagaimana tersebut di atas, maka penempatannya harus berdasarkan kebutuhan. Rambu lalu lintas dan marka jalan di kota Ternate penempatannya sebagian kurang memberikan informasi dan mengarahkan lalu lintas sementara itu sebagian jalan di Kota Ternate belum lengkap marka jalanya selain itu diperlukan penambahan rambu-rambu jalan seiring dengan perkembangan Kota Ternate.

\subsection{METODE PENELITIAN}

Penelitian ini dilaksanakan dengan cara peninjauan langsung di lapangan dan studi literatur. Hal ini sangat diperlukan untuk mengetahui kondisi eksisting lokasi serta kondisi lingkungan sekitarnya. Kemudian data yang diperoleh dari lapangan diolah dan dibandingkan dengan standar rambu dan marka yang berlaku.

\subsection{Lokasi Penelitian}

Penelitian ini dilakukan di Kota Ternate pada jaringan jalan yang memiliki kepadatan arus lalu lintas yang cukup tinggi. Ruas jalan yang ditinjau adalah Jalan Merdeka, dan Jalan Ahmad Yani.

\subsection{Teknik Pengambilan Data \\ 2.2.1. Tahap Persiapan}

Dalam tahap ini disusun hal-hal penting yang harus segera dilakukan dengan tujuan dapat mengefektifkan waktu dan pekerjaan. Sebelum dilaksanakan pengambilan data secara lengkap, dilakukan survei pendahuluan.

\subsubsection{Langkah Pengambilan Data}

Berdasarkan hasil pengamatan pada survei pendahuluan, berikut ini adalah langkah pengambilan data dilapangan.

a. Data Primer

Data primer adalah data yang dikumpulkan ataupun diperoleh langsung di lapangan. Tujuan dari pengambilan data primer adalah untuk mencari data yang sifatnya merupakan data yang memiliki tingkat keakuratan yang tinggi. Diantaranya yaitu survei kondisi eksisting rambu dan marka jalan di ruas jalan Merdeka, dan Jalan Ahmad Yani.

b. Data Sekunder

Data sekunder berupa data penunjang yang dikumpulkan melalui studi kepustakaan yang diambil dari instansiinstansi terkait seperti Kementrian Pekerjaan Umum, dan Dinas Perhubungan. Data sekunder ini antara lain:

1. Peta lokasi penempatan rambu dan marka jalan di Kecamatan Ternate Barat.

2. Gambar desain geometrik ruas jalan wilayah studi. 


\subsection{Teknik Analisa Data}

Dalam melaksanakan survey fasilitas kelengkapan jalan, yang perlu diamati dalam tinjauan ini adalah tentang penempatan dan pengaturan rambu seperti : marka, pagar pengaman (guardrail), serta alat pengatur dan pengaman lainnya. Hubungan antara rambu, marka dan geometrik jalan akan dianalisis dengan model perbandingan dengan standar Departemen Perhubungan serta digambarkan penempatan rambu dan marka berdasarkan Keputusan Menteri Perhubungan Republik Indonesia No. 61 Tahun 1993.

Berikut tahapan Analisa data yang akan dilakukan :

a. Keseragaman bentuk, ukuran dan pemeliharaan rambu lalu lintas.

b. Penyesuaian penempatan marka dengan geometrik jalan.

c. Rekomendasi penempatan dan pemasangan rambu dan marka di titk - titik tertentu yang belum terpasang di ruas jalan Merdeka dan Ahmad Yani.

\subsection{HASIL DAN PEMBAHASAN}

\subsection{Data Sekunder}

Tabel 1. Data Ruas Jalan

\begin{tabular}{|c|c|c|c|c|}
\hline \multicolumn{2}{|c|}{ NOMOR } & NAMA RUAS & PANJANG $(\mathbf{K m})$ & KLASIFIKASI \\
\hline URUT & RUAS & & & \\
\hline 1 & $026 / 14 / \mathrm{K}$ & Jl. Merdeka & 0,480 & Kolektor Primer $(\mathrm{K} 1)$ \\
\hline 2 & $026 / 16 / \mathrm{K}$ & Jl. Ahmad Yani & 0,490 & Kolektor Primer $(\mathrm{K} 1)$ \\
\hline
\end{tabular}

Sumber : SK Mentri PU No. 631 Tahun 2009

\subsection{Data Primer}

\subsubsection{Rambu Jalan}

a. Ruas Jalan Merdeka

Tabel 2. Penempatan Rambu Pada Ruas Jalam Merdeka Arah Selatan ke Utara

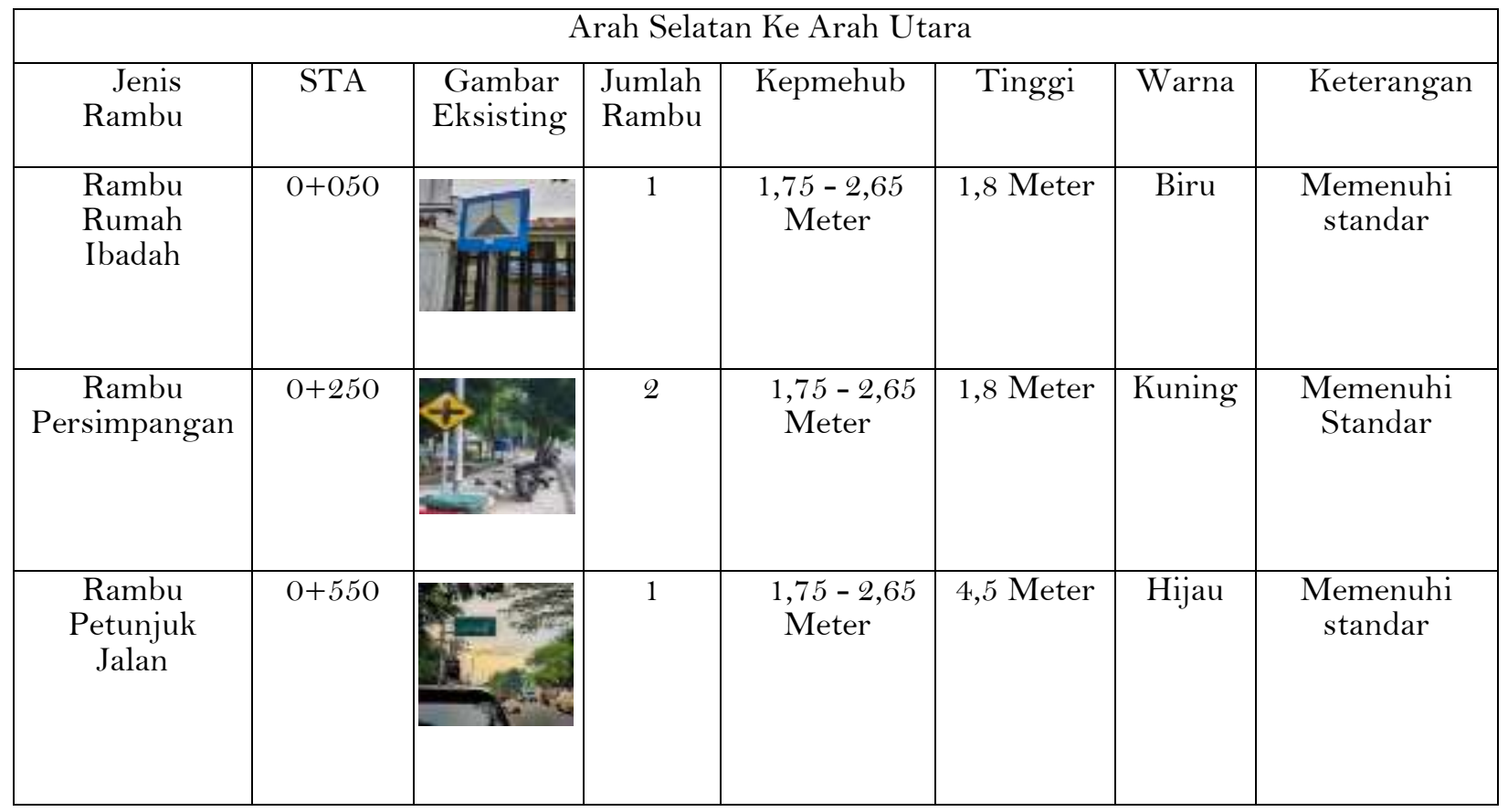


Tabel 3. Penempatan Rambu Pada Ruas Jalan Merdeka Arah Utara ke Selatan

\begin{tabular}{|c|c|c|c|c|c|c|c|}
\hline \multicolumn{9}{|c|}{ Arah Selatan Ke Arah Utara } \\
\hline Jenis Rambu & STA & $\begin{array}{c}\text { Gambar } \\
\text { Eksisting }\end{array}$ & $\begin{array}{c}\text { Jumlah } \\
\text { Rambu }\end{array}$ & Kepmehub & Tinggi & Warna & Keterangan \\
\hline $\begin{array}{c}\text { Rambu } \\
\text { Traffic Light }\end{array}$ & $0+275$ & 1 & $\begin{array}{c}1,75-2,65 \\
\text { Meter }\end{array}$ & 1,9 Meter & Kuning & $\begin{array}{c}\text { Memenuhi } \\
\text { standar }\end{array}$ \\
\hline $\begin{array}{c}\text { Rambu } \\
\text { Jalan }\end{array}$ & $0+325$ & Sals & 1 & $\begin{array}{c}1,75- \\
2,65 \text { Meter }\end{array}$ & 1,8 Meter & Hijau & $\begin{array}{c}\text { Memenuhi } \\
\text { Standar }\end{array}$ \\
& & & & & & & \\
\hline
\end{tabular}

Pada ruas jalan Merdeka, masih di perlukan penambahan rambu-rambu lalu lintas dan rambu fasilitas umum antara lain : rambu pejalan kaki, rambu penyebrangan, rambu restaurant dan rambu gelanggang olahraga. Tujuannya adalah agar pengendara lebih aman dan nyaman saat mencari tempat fasilitas umum.

\section{b. Ruas Jalan Ahmad Yani}

Tabel 4. Penempatan Rambu Pada Ruas Jalan Ahmad Yani Arah Barat ke Arah Timur

\begin{tabular}{|c|c|c|c|c|c|c|c|}
\hline \multicolumn{8}{|c|}{ Arah Utara Barat Ke Arah Timur } \\
\hline Jenis Rambu & STA & $\begin{array}{l}\text { Gambar } \\
\text { Eksisting }\end{array}$ & $\begin{array}{l}\text { Jumlah } \\
\text { Rambu }\end{array}$ & Kepmehub & Tinggi & Warna & Keterangan \\
\hline $\begin{array}{l}\text { Rambu Nama } \\
\text { Jalan }\end{array}$ & $\begin{array}{c}\mathrm{O}+\mathrm{OOO} \\
\& \\
\mathrm{O}+175\end{array}$ & & 2 & $\begin{array}{l}1,75-2,65 \\
\text { Meter }\end{array}$ & $\begin{array}{c}2,2 \\
\text { Meter }\end{array}$ & Hijau & $\begin{array}{l}\text { Memenuhi } \\
\text { standar }\end{array}$ \\
\hline $\begin{array}{c}\text { Rambu } \\
\text { persimpangan }\end{array}$ & $0+100$ & & 1 & $\begin{array}{l}1,75-2,65 \\
\text { Meter }\end{array}$ & $\begin{array}{c}1,8 \\
\text { Meter }\end{array}$ & $\begin{array}{l}\text { Kuning } \\
\text { Hitam }\end{array}$ & $\begin{array}{l}\text { Memenuhi } \\
\text { Standar }\end{array}$ \\
\hline $\begin{array}{c}\text { Rambu } \\
\text { Larangan Parkir }\end{array}$ & $\begin{array}{c}0+225 \\
\& \\
0+325\end{array}$ & & 2 & $\begin{array}{l}1,75-2,65 \\
\text { Meter }\end{array}$ & $\begin{array}{c}2,2 \\
\text { meter }\end{array}$ & $\begin{array}{l}\text { Putih } \\
\text { Merah }\end{array}$ & $\begin{array}{l}\text { Memenuhi } \\
\text { Standar }\end{array}$ \\
\hline $\begin{array}{c}\text { Rambu } \\
\text { larangan Stop }\end{array}$ & $0+335$ & & 1 & $\begin{array}{l}1,75-2,65 \\
\text { Meter }\end{array}$ & $\begin{array}{c}2,2 \\
\text { Meter }\end{array}$ & $\begin{array}{l}\text { Putih } \\
\text { Merah }\end{array}$ & $\begin{array}{l}\text { Memenuhi } \\
\text { Standar }\end{array}$ \\
\hline
\end{tabular}


Tabel 5. Penempatan Rambu Pada Ruas Jalan Ahmad Yani Arah Timur ke Arah Barat

\begin{tabular}{|c|c|c|c|c|c|c|c|}
\hline Jenis Rambu & STA & $\begin{array}{l}\text { Gambar } \\
\text { Eksisting }\end{array}$ & $\begin{array}{l}\text { Jumlah } \\
\text { Rambu }\end{array}$ & Kepmehub & Tinggi & Warna & Keterangan \\
\hline $\begin{array}{c}\text { Rambu Traffic } \\
\text { light }\end{array}$ & $0+175$ & & 1 & $\begin{array}{l}1,75-2,65 \\
\text { Meter }\end{array}$ & $\begin{array}{c}2,2 \\
\text { Meter }\end{array}$ & Kuning & $\begin{array}{l}\text { Memenuhi } \\
\text { standar }\end{array}$ \\
\hline $\begin{array}{c}\text { Rambu Larangan } \\
\text { Parkir }\end{array}$ & $\begin{array}{c}\mathrm{O}+225 \\
\& \\
\mathrm{O}+300\end{array}$ & & 2 & $\begin{array}{l}1,75-2,65 \\
\text { Meter }\end{array}$ & $\begin{array}{c}1,9 \& \\
2,2 \\
\text { Meter }\end{array}$ & $\begin{array}{l}\text { Putih } \\
\text { Merah }\end{array}$ & $\begin{array}{l}\text { Memenuhi } \\
\text { Standar }\end{array}$ \\
\hline $\begin{array}{c}\text { Rambu larangan } \\
\text { Stop }\end{array}$ & $0+335$ & & 1 & $\begin{array}{l}1,75-2,65 \\
\text { Meter }\end{array}$ & $\begin{array}{c}2,2 \\
\text { meter }\end{array}$ & $\begin{array}{l}\text { Putih } \\
\text { Merah }\end{array}$ & $\begin{array}{l}\text { Memenuhi } \\
\text { standar }\end{array}$ \\
\hline
\end{tabular}

Untuk ruas jalan ini terdapat 6 rambu, dimana masih terdapat rambu-rambu yang belum di tempatkan seperti rambu fasilitas umum, rambu persimpangan, rambu peringatan dan rambu perintah.

\subsubsection{Marka Jalan}

\section{a. Ruas Jalan Merdeka}

Tabel 6. Kondisi Marka Pada Ruas Jalan Merdeka

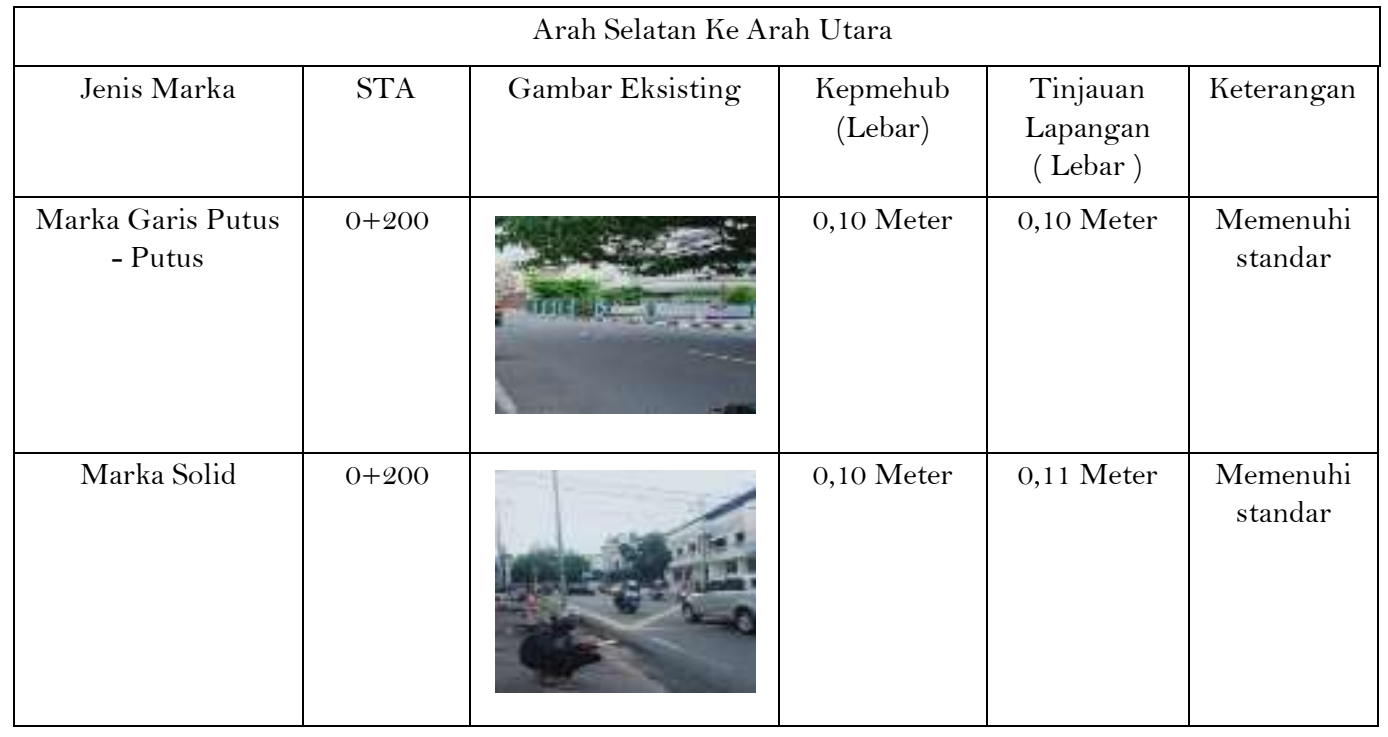

Ruas jalan ini terdapat marka membujur berupa garis putus-putus, pembatas jalur pada jalan 2 (dua) arah dan mengarahkan lalu lintas pada jalan tersebut. Marka membujur berupa garis solid atau menerus ini di gunakan pada penyebrangan Zebra cross. Marka tidak memenuhi standar, terlihat pada warna yang telah memudar. Di perlukan pengecatan kembali agar marka terlihat jelas oleh pengendara. 


\section{b. Ruas Jalan Ahmad Yani}

Tabel 7. Kondisi Marka Pada Ruas Jalan Ahmad Yani

\begin{tabular}{|c|c|c|c|c|c|}
\hline \multicolumn{6}{|c|}{ Arah Barat ke Timur } \\
\hline Jenis Marka & STA & $\begin{array}{l}\text { Gambar } \\
\text { Eksisting }\end{array}$ & $\begin{array}{c}\text { Kepmehub } \\
\text { (Lebar) }\end{array}$ & $\begin{array}{c}\text { Tinjauan } \\
\text { Lapangan } \\
\text { ( Lebar ) }\end{array}$ & Keterangan \\
\hline $\begin{array}{c}\text { Marka Garis Putus - } \\
\text { Putus }\end{array}$ & $0+200$ & & o,10 Meter & o,10 Meter & $\begin{array}{l}\text { Memenuhi } \\
\text { standar }\end{array}$ \\
\hline Marka Solid & $0+200$ & & o,10 Meter & o,11 Meter & $\begin{array}{l}\text { Memenuhi } \\
\text { standar }\end{array}$ \\
\hline
\end{tabular}

Untuk ruas jalan ini terdapat marka membujur berupa garis putus-putus ini menjadi pembatas jalur pada jalan 2 (dua) arah dan mengarahkan lalu lintas pada jalan tersebut. Garis putus-putus ini sudah memenuhi standar karena sudah di cat dan dapat terlihat oleh pengendara.

Marka membujur berupa garis solid atau menerus ini di gunakan membatasi antara tempat pemberhentian kendaraan dengan lalu lintas pejalan kaki yang di sebut zebra cross. Marka ini sudah memenuhi standar.

\section{KESIMPULAN}

Dari pembahasan kondisi rambu dan marka jalan di ruas jalan Merdeka dan jalan Ahmad Yani Kota Ternate yang telah di uraikan sebelumnya, maka ada beberapa hal yang dapat di simpulkan yaitu:

a. Masih terdapat rambu lalu lintas yang tidak terawat dan kondisi rambu yang rusak. Di perlukan perbaikan pada daun rambu dan pengecatan kembali.

b. Pada beberapa rambu penunjuk jurusan, bentuk dan ukuran tulisan tidak memenuhi standar Kepmen RI No. 61 Tahun 1993.

c. Rekomendasi penempatan rambu dan marka pada ruas jalan yang belum lengkap fasilitas perlengkapan jalan yaitu sebagai berikut : rambu perempatan, rambu pertigaan, rambu penyebrangan, serta rambu petunjuk fasilitas umum.

\section{References}

[1] Arianto S.B, Heriwibowo D, 2016, Evaluasi Kebutuhan Rambu Lalu Lintas Pada Ruas Jalan Perbatasan Antara Kabupaten Bantul-Gading Di Gunungkidul, Yogyakarta. Jurnal Teknik Sipil (Online).

[2] Ditjen Bina Marga, 1991. Petunjuk Perencanaan Marka Jalan

[3] Ditjen Bina Marga, 1991. Tata Cara Pemasangan Rambu dan Marka Jalan Perkotaan

[4] Firgian H, Sulandari E, Mayuni S, 2014, Evaluasi Keberadaan Rambu dan Marka Jalan di Kota Pontianak. Jurnal Teknik Sipil (Online).

[5] Hermansyah T. 2014. Keserasian Lampu dan Marka Terhadap Geometrik Jalan pada Jalan Antar Kota, Studi Kasus (Ruas Jalan Banda Aceh KM-77 Batas Pidie. Tesis. Banda Aceh. Program Studi Magister Teknik Sipil Program Pascasarjana Universitas Syiah Kuala Darussalam

[6] Haryadi, Adi, Juni 2012. Harmonisasi Rambu dan Marka dengan Geometrik Jalan Pada Jalan Luar Kota . Depok.

[7] Kementerian Perhubungan. 1993. Keputusan Menteri No. 61 tentang Rambu-Rambu Lalu Lintas di Jalan.

[8] Peraturan Menteri Perhubungan Republik Indonesia No.43, 1993. Tentang Prasarana dan Lalu Lintas Jalan 
[9] Peraturan Menteri Perhubungan Republik Indonesia No.13, 2014. Tentang Rambu Lalu Lintas

[10] Utami MS, Sukirman S. 2016. Kajian kelengkapan perlengkapan jalan pada Jalan Pelajar Pejuang Bandung. Jurnal Online Institut Teknologi Nasional. 20(10): 1-12 